\title{
Angle Closure Glaucoma Secondary to Enlarged Soemmering Ring That is Clinically Similar to Iris Tumour
}

\section{Babak Masoomian (D) \\ Maryam Saatchi \\ Fariba Ghassemi (D) \\ Hamid Riazi-Esfahani (D) \\ Zakieh Vahedian}

Ocular Oncology Service, Farabi Eye Hospital, Tehran University of Medical

Sciences, Tehran, Iran
Correspondence: Babak Masoomian Ocular Oncology Service, Farabi Eye Hospital, Kargar Street, Qazvin Square, Tehran, Iran

Tel $+9821-55426283$

Fax +98 2I-55409092

Email drmasomian@gmail.com
This article was published in the following Dove Press journal: International Medical Case Reports Journal

Purpose: To report a case of a grown Soemmering ring that manifested as an iris tumour 24 years after cataract surgery.

Methods: A case report.

Results: A 27-year-old white man was presented with a suspected iris tumour in his left eye. He had undergone lensectomy in both eyes without intraocular lens implantation 24 years ago. Last year, he was treated by topical anti-glaucoma medication for left eye intraocular pressure (IOP) rising. Six months later, his ophthalmologist found two separate iris bumps. The patient was referred to an ocular oncologist and was to be treated with plaque brachytherapy as iris melanoma, but he denied. Ultrasound biomicroscopy (UBM) of the left eye showed significant angle narrowing due to separate ovoid hyper echoic masses behind the iris, which was clearly separated from the ciliary body. Retained and growth lens material caused a Soemmering ring to enlarge, which was the reason for glaucoma and iris bumping. The patient has been followed for more than one year without any changes being observed.

Conclusion: An enlarged and grown Soemmering ring should be considered in the differential diagnosis of any iris and ciliary body tumour, especially in patients who have had cataract surgery.

Keywords: eye, cataract surgery, iris, tumour, glaucoma, Soemmering ring

\section{Introduction}

Iris melanoma is a rare type of tumour and accounts for $3-10 \%$ of all uveal melanomas. ${ }^{1,2}$ It usually presents itself as a gradually enlarging pigmented mass, and most patients report a new growth in a longstanding stable nevus. ${ }^{1,2}$ Clinical findings included distorted pupil, ectropion uvea, localized cataract, prominent iris vascularization, and angle involvement. ${ }^{3}$ Although prompt diagnosis and rapid treatment are of great importance, considering other possible differential diagnoses and valid interpretations of para-clinical findings for accurate diagnosis are also valuable. There is a range of benign and malignant lesions in the differential diagnosis of iris melanoma ${ }^{1}$ even though in a study of 200 patients with iris melanoma, Soemmering rings did not appear in the differential diagnosis. 4

Herein, we offer an unusual presentation of a Soemmering ring 24 years after cataract surgery, in which the patient was supposed to be treated as iris melanoma. 


\section{Case Report}

A 27-year-old man diagnosed with left eye iris melanoma was referred to ocular oncology service at Farabi Eye Hospital. He had undergone lensectomy without intraocular lens implantation in both eyes for congenital cataracts 24 years earlier.

One year before this report, during a yearly eye examination, high intraocular pressure $(28 \mathrm{~mm} \mathrm{Hg})$ was detected in his left eye, and he has since been treated with Cosopt eye drops $(20 \mathrm{mg} / \mathrm{mL}$ Dorzolamide $+5 \mathrm{mg} /$ $\mathrm{mL}$ Timolol). The intraocular pressure (IOP) was superbly regulated. After six months, his ophthalmologist noticed left eye iris bumping in the supra-temporal and infra-nasal quadrants (Figure 1). Ultrasound biomicroscopy (UBM) showed two ovoid hyperechoic masses behind the iris tissue, which caused a narrowing of angle, and it was clearly separated from the ciliary body (Figure 2). Given that UBM provides two-dimensional images, the section taken by UBM appears to belong to a doughnut-shaped lesion, which was the thickest in two places.

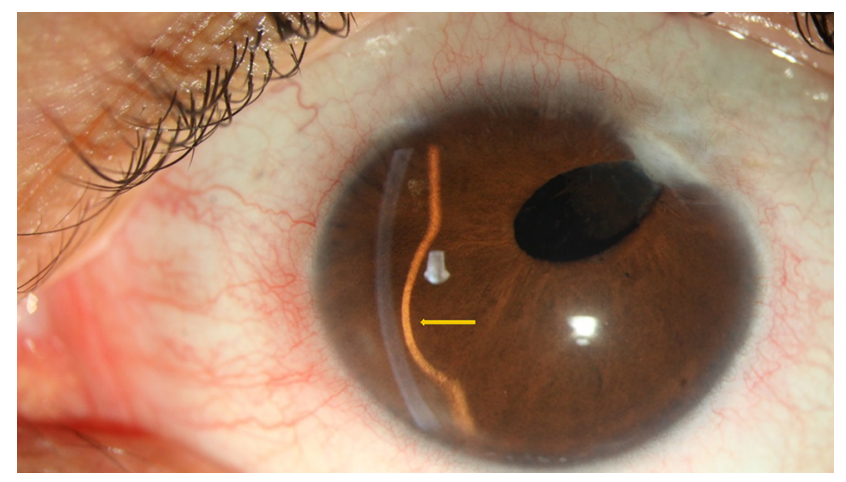

Figure I Slit-lamp photograph of the left eye showing opacity in cornea incision site with aphakia. The yellow arrow shows remarkable iris bulging in inferonasal quadrant.
After his diagnosis of iris melanoma, the patient was referred to an ocular oncologist and became a candidate for plaque radiotherapy, but the patient refused. Finally, he was referred to an oncology service at Farabi Eye Hospital for investigation.

In a routine eye examination, refraction was measured as $+6.5 \mathrm{OD}$ for the right eye (OD) and +7.00 D for the left eye (OS), and his best-corrected visual acuities were 20/25 OD and 20/30 OS.

In a slit-lamp examination, his right eye was aphakic and otherwise unremarkable. On his left eye, iris bumping was noticed in two quadrants and showed no transillumination (Figure 2). Pre-limbal scleral and conjunctival structures were unremarkable, and there was no sentinel vessel or extra scleral tumour extension. Intraocular pressures were $14 \mathrm{mmHg}$ for OD and $18 \mathrm{mmHg}$ for OS by taking Cosopt eye drop. In gonioscopy, the superotemporal and inferonasal angles were closed (Schwalbe's line was not visible) with no synechia on indentation. The pupil was miotic and did not dilate enough to visualize the posterior border of the lesion, and it was impossible for the mass to be visualized gonioscopically. Also, no iris and angle neovascularization (NVI) or pigmented seeding were detected.

According to his past ocular history and clinical and UBM findings, the patient's diagnosis was retained, and growth lens material was detected behind the iris (Soemmering ring), which causes secondary angle-closure glaucoma. He was followed with only anti-glaucoma medication, and after 18 months, no changes were noticed.

\section{Discussion}

Differentiation between benign and malignant lesions, mainly those located in the iris, is still challenging. ${ }^{1}$ Iris

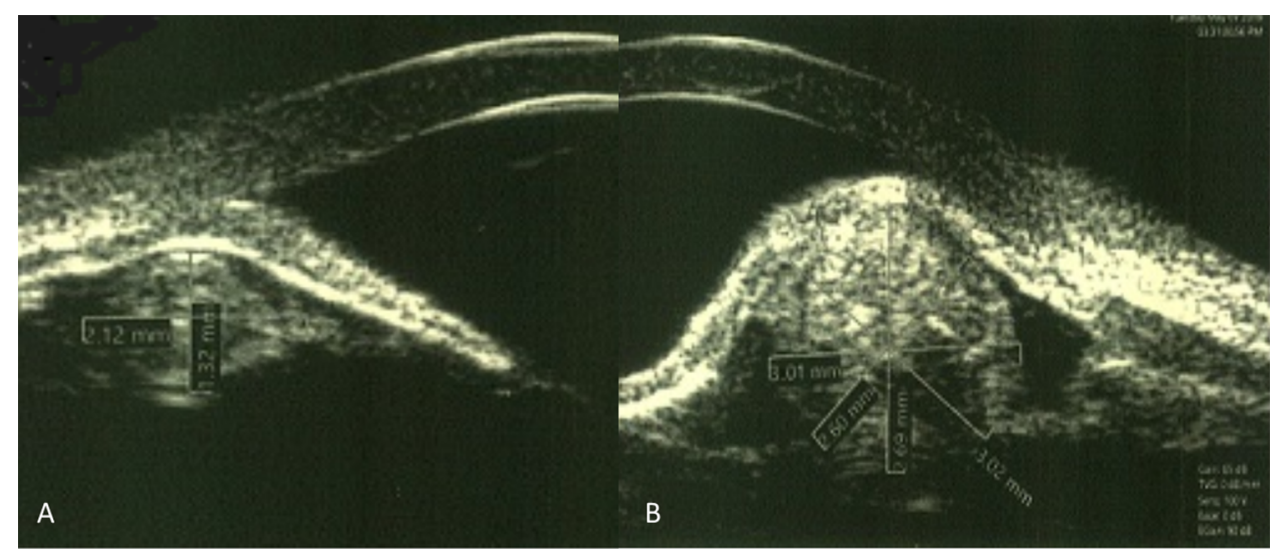

Figure 2 In UBM imaging of the left eye, Ovoid hyperechoic structures cause iris bombe in supra- temporal (A) and inferonasal (B) quadrants. Significant closure of anterior chamber angle is visible in both pictures. 
melanoma is a potentially fatal tumour that can be simulated by a wide variety of iris lesions. ${ }^{1-3}$

These lesions range from nevus, melanoma, cysts, and metastasis. ${ }^{1,2}$ They can be broadly categorized into cystic $(21 \%)$ or solid $(79 \%)$ lesions. ${ }^{1}$ Except for in specific cases, iris melanoma diagnosis is based on clinical and paraclinical findings. ${ }^{5}$ The differentiation is evident on slit-lamp examination and confirmed by ocular imaging, which is principally done using Ultrasound biomicroscopy (UBM). ${ }^{5,6}$ UBM is particularly valuable for evaluations of iris lesion ciliary body melanomas or uveal tumours with ciliary body extension. In an analysis of 200 consecutive eyes with iris tumours, Bianciotto et al showed that compared to anterior segment OCT, UBM provided better overall tumour visualization and better posterior margin resolution. ${ }^{7}$ Importantly, slit-lamp examinations, gonioscopy, indirect ophthalmoscopy, and transillumination might not reveal the extent of a tumour within the iris and ciliary body stromal. ${ }^{6}$

Iris melanoma is a malignant neoplasm that arises from melanocytes and appears as a variably pigmented, welldefined mass in the iris stroma (anterior surface). Other clinical variations of iris melanoma include diffuse, trabecular meshwork, and tapioca melanoma. ${ }^{3}$

Few lesions occur on the posterior surface of the iris, including Iris Pigment Epithelium (IPE) cysts (most common), iris pigmented epithelium adenoma, and extensive ciliary body melanoma. All these lesions can mimic the clinical features of iris melanoma. ${ }^{8}$

- A Soemmering ring is caused by retained lens material or the proliferation of lenticular epithelial cells. After cataract surgery, the adhesion of anterior and posterior capsular leaflets at the capsular periphery may occur and lead to the formation of a circumferential structure. This is usually seen in patients who have had lensectomy early in their lives. ${ }^{9}$ It usually remains undiagnosed behind the iris unless its increased volume renders it apparent or it is dislodged and migrates into the pupil, anterior chamber, or vitreous. ${ }^{10}$ A Soemmering ring can induce progressive synechial angle closure without pupillary blocking due to its enlargement. ${ }^{9,10}$

Suwan reported three patients with angle-closure due to Soemmering rings for which UBM demonstrated a large circumferential hyperechoic doughnut-shaped structure behind the iris surface, which caused pupillary blocking. ${ }^{10}$ In a study on 3680 cases of iris tumours by Shields et al, Soemmering rings did not appear in the differential diagnosis. ${ }^{12}$ Watts and Rennie presented a case of a 61-year-old woman (50 years after cataract surgery) who was initially misdiagnosed with an iris tumour. UBM revealed a large asymmetrical Soemmering ring, indenting iris inferiorly. ${ }^{11}$

Based on previous reports, Soemmering rings occur most prominently in patients who have undergone lensectomy early in life, especially for patients who did not undergo intra-bag IOL implantation. ${ }^{13}$ Less likely, congenital aphakia and its association with systemic syndromes (ie, Lowe syndrome or Hallermann-Streiff-François syndrome) can cause Soemmering rings. ${ }^{13}$ These rings can grow and frequently dislocate, especially in myopic eyes where the zonular fibers are weak and the vitreous is liquefied, which allows Soemmering ring displacement. ${ }^{10}$ In this aforementioned patient, 24 years after cataract surgery, the growth of retained lens material in the aphakic left eye caused angle closure glaucoma and iris bumping. This enabled a diagnosis to be made via UBM without any justification for a more invasive procedure.

In conclusion, the effects of previous ocular surgeries, no matter how long ago, must always be considered in the differential diagnosis of suspected lesions. Therefore, the diagnosis of Soemmering rings should be considered in the differential diagnosis of iris and ciliary body tumours, particularly in previous cataract surgery cases.

Written Informed consent for publication of the case details and accompanying images was obtained from the patient. Institutional review board approval was obtained from Farabi Eye Hospital. This study adhered to the tenets of the Declaration of Helsinki.

\section{Author Contributions}

All authors made a significant contribution to the work reported, whether that is in the conception, study design, execution, acquisition of data, analysis and interpretation, or in all these areas; took part in drafting, revising or critically reviewing the article; gave final approval of the version to be published; have agreed on the journal to which the article has been submitted; and agree to be accountable for all aspects of the work.

\section{Disclosure}

The authors report no conflicts of interest in this work. 


\section{References}

1. Shields CL, Shields PW, Manalac J, Jumroendararasame C, Shields JA. Review of cystic and solid tumors of the iris. Oman J Ophthalmol. 2013;6(3):159-164. doi:10.4103/0974-620X.122269

2. Kersten RC, David TT, Anderson R. Iris melanoma. Nevus or malignancy? Surv Ophthalmol. 1985;29(6):423-433. doi:10.1016/ 0039-6257(85)90207-3

3. Conway RM, Chua WC, Qureshi C, Billson FA. Primary iris melanoma: diagnostic features and outcome of conservative surgical treatment. $B r \quad J$ Ophthalmol. 2001;85(7):848-854. doi:10.1136/ bjo.85.7.848

4. Shields JA, Sanborn GE, Augsburger JJ. The differential diagnosis of malignant melanoma of the iris: a clinical study of 200 patients. Ophthalmology. 1983;90(6):716-720. doi:10.1016/S0161-6420(83) 34500-0

5. Marigo FA, Finger PT, McCormick SA, et al. Iris and ciliary body melanomas: ultrasound biomicroscopy with histopathologic correlation. Arch Ophthalmol. 2000;118(11):1515-1521. doi:10.1001/ archopht.118.11.1515

6. Giuliari GP, McGowan HD, Pavlin CJ, Heathcote JG, Simpson ER. Ultrasound biomicroscopic imaging of iris melanoma: a clinicopathologic study. Am J Ophthalmol. 2011;151(4):579-585. doi:10.1016/j.ajo.2010.09.024
7. Bianciotto C, Shields CL, Guzman JM, et al. Assessment of anterior segment tumors with ultrasound biomicroscopy versus anterior segment optical coherence tomography in 200 cases. Ophthalmology. 2011;118(7):1297-1302. doi:10.1016/j.ophtha.2010.11.011

8. Shields JA, Shields CL, Mercado G, Gündüz K, Eagle RC Jr. Adenoma of the iris pigment epithelium: a report of 20 cases: the 1998 Pan-American Lecture. Arch Ophthalmol. 1999;117 (6):736-741. doi:10.1001/archopht.117.6.736

9. Akal A, Göncü T, Yuvaci I, Pangal E, Cakmak S. Pupil occlusion due to a large dislocated Soemmering ring in an aphakic eye. Int Ophthalmol. 2014;34(1):121-124. doi:10.1007/s10792-0139745-3

10. Suwan Y, Purevdorj B, Teekhasaenee C, Supakontanasan W, Simaroj P. Pseudophakic angle-closure from a Soemmering ring. BMC Ophthalmol. 2016;16:91. doi:10.1186/s12886-016-0257-6

11. Watts AR, Rennie IG. Soemmering's ring presenting as an iris tumour. Eye. 1998;12:1021-1023. doi:10.1038/eye.1998.264

12. Shields CL, Kancherla S, Patel J, et al. Clinical survey of 3680 iris tumors based on patient age at presentation. Ophthalmology. 2012;119(2):407-414. doi:10.1016/j.ophtha.2011.07.059

13. Wilson ME Jr, Englert JA, Greenwald MJ. In-the-bag secondary intraocular lens implantation in children. JAAPOS. 1999;3:350-355.

\section{Publish your work in this journal}

The International Medical Case Reports Journal is an international, peer-reviewed open-access journal publishing original case reports from all medical specialties. Previously unpublished medical posters are also accepted relating to any area of clinical or preclinical science. Submissions should not normally exceed 2,000 words or 4 published pages including figures, diagrams and references. The manuscript management system is completely online and includes a very quick and fair peer-review system, which is all easy to use. Visit http://www.dovepress.com/testimonials.php to read real quotes from published authors. 